Evidencing the impact of

teaching-related CPD: beyond the

\title{
'Happy Sheets'
}

\section{Spowart, Lucy}

http://hdl.handle.net/10026.1/10035

\subsection{0/1360144X.2017.1340294 \\ International Journal for Academic Development \\ Informa UK Limited}

All content in PEARL is protected by copyright law. Author manuscripts are made available in accordance with publisher policies. Please cite only the published version using the details provided on the item record or document. In the absence of an open licence (e.g. Creative Commons), permissions for further reuse of content should be sought from the publisher or author. 


\section{Evidencing the Impact of Teaching-related CPD: Beyond the 'Happy Sheets'}

This is the author's accepted manuscript. The final published version of this work (the version of record) is published by Taylor \& Francis in The International Journal of Academic Development (published online 29 June 2017) available at: http://www.tandfonline.com/doi/full/10.1080/1360144X.2017.1340294 Acceptance Date: 14 January 2017

\section{Lucy Spowart, Jennie Winter, Rebecca Turner, Reema Muneer, Colleen McKenna and Pauline Kneale}

Pedagogic Research and Observatory, Plymouth University, Plymouth, UK

Corresponding author: Dr Lucy Spowart, Associate Professor in Postgraduate Clinical Education, Peninsula Schools of Medicine and Dentistry, John Bull Building, Plymouth, PL6 8BU.

Biographical notes

Dr Lucy Spowart is an Associate Professor in Clinical Education at Plymouth University and Senior Fellow of the HEA. Her main research interests are in CPD, evaluation of teaching, community engagement, and student parents.

Dr Jennie Winter is an Associate Professor in Educational Development at Plymouth University. Her research interests include: evaluation of teaching in HE, education for sustainable development and inclusivity.

Dr Rebecca Turner is an Educational Developer at Plymouth University. Her research interests include examining the role of research and scholarship in college-based HE, the contribution evaluation can make to educational development practice and student transitions. 
Reema Muneer is a Research Assistant at Plymouth University. She is currently engaged in research on student learning gain and the experiences of under-represented groups in HE.

Dr Colleen McKenna is an Academic Developer at the London School of Economics and Political Science. She is also Partner/Researcher at HE Development, Evaluation, Research

Professor Pauline Kneale is Pro Vice-Chancellor Teaching and Learning at Plymouth University, Director of the Pedagogic Research Institute and Observatory and a National Teaching Fellow.

This work was supported by the Higher Education Academy under Grant RT03 


\section{Evidencing the Impact of Teaching-related CPD: Beyond the 'Happy Sheets'}

In this paper we report the outcomes of a national survey of academic development staff in a range of UK HE Institutions to consider the approaches adopted to evaluate teaching-related CPD. Despite the increasing drive towards accountability, the majority of respondents undertook no benchmarking to establish existing knowledge, there was minimal use of existing data sets, and few evaluated provision longitudinally. We argue that in order to arrive at an evidence-informed approach, evaluation and teaching-related CPD must be clearly conceptualised, and aligned with institutional priorities. The involvement of students to staff CPD could also be usefully explored.

Keywords: accountability; evaluation of impact; evidence-informed; professionalisation of $\mathrm{HE}$

\section{Introduction}

While there is an increasingly explicit expectation of 'value for money delivery' in the 'marketised' higher education (HE) sector, all aspects of HE need to demonstrate effectiveness and impact (Alexander, 2000; Hoecht, 2006). Impact in many areas needs to be understood in terms of 'change', which is meaningful, and lasting (De Rijdt, Stes, van der Vleuten, \& Dochy, 2013). For those involved in continual professional development (CPD) activities with academic and professional staff the impact is initially with the staff who are engaged in these CPD activities (Bamber, 2013). However, they in turn employ the ideas generated through this CPD with their students, colleagues and other aspects of their work. Consequently, 'evidencing impact' of the work of academic development units is challenging due to the indirect influences involved (De Rijdt et al., 2013; Gibbs, 2010). Nonetheless, there is a need to understand the ways in which CPD influences teaching quality and student learning (Brew, 2007; 
Chalmers \& Gardiner, 2015; Sword, 2008).

CPD is a wide-ranging term and how it is defined and used has implications for what can be researched and claimed (De Ridjt et al., 2013). In the current context, CPD is defined as any activity "targeted to strengthen and extend the knowledge, skills and conceptions of HE educators in a way that will lead to changes in their way of thinking and their educational behaviour" (Fenstermacher \& Berliner, 1985, p. 49). We also take CPD to encompass what is often referred to as 'academic development'. A review of extant research (e.g. Hughes et al., 2016; Parsons, Hill, Holland, \& Willis, 2012) underlines the diversity of CPD provision and highlights a distinction between CPD provision for new HE teachers and activities for more experienced colleagues.

For early career lecturers, CPD tends to be focused on accredited programmes, such as postgraduate certificates, that introduce the practices of university teaching and supporting student learning (Parsons et al., 2012). Established academics commonly engage with non-accredited CPD activities such as workshops, projects, conferences, activities related to the scholarship of teaching and learning (SoTL) and, more recently, schemes to provide recognition of their teaching expertise (Spowart, Turner, Shenton, \& Kneale, 2015). To evaluate this spectrum of activity, data must be captured from an institution's formal CPD offer including accredited courses, as well as its informal, nonaccredited CPD offer. To complicate things further, much of an academic's CPD may take place outside of their own institution and within their discipline context.

Capturing meaningful evaluation data is complex, and the challenges of evidencing the impact of teaching-related CPD are shared across the international academic development community (Chalmers \& Gardiner, 2015; De Ridjt et al., 2013; Fink, 2013; Sword, 2014). Chalmers and Gardiner (2015) argue that in the absence of 
rigorous and relevant evaluation tools, CPD programmes will continue to be assessed with blunt and limited, snapshot instruments. Typically, these are participant satisfaction surveys, administered at the end of a session or programme, which cannot capture the richer, contextualised, longer-term impacts (Chalmers \& Gardiner, 2015). This practice is also prevalent in the UK (Bamber, 2013). The reflections of staff at the end of a CPD session, and their speculations on their future deployment of new ideas are interesting, but are at best a proxy measure of impact and effectiveness of the CPD intervention (Bamber, 2013).

Furthermore, most evaluation of CPD fails to consider impacts upon student experience and outcomes. Despite widespread moves to empower student engagement within HE and to involve students in curriculum design and innovation work though agendas such as 'students as partners' (Buckley, 2014), student engagement in lecturer CPD has been somewhat overlooked (Turner et al., 2016). This may be partly due to the perceived challenges, such as accessing students at the time when CPD is taking place, and concerns over the receptiveness of academic staff to student feedback (Campbell, Eland, Rumpus, \& Shacklock, 2009). However, the absence of student input to lecturer CPD may go some way to explaining the 'substantial lack of direct evidence on outcomes for students' (Parsons, Hill, Holland, and Willis, 2012, p.32). Additionally, reviews of existing research into evaluation of CPD highlighted methodological limitations such as small sample sizes, ambiguous methodological frameworks and localised contexts (Chalmers \& Gardiner, 2015). In the literature review commissioned as part of this project (Hughes et al. 2016), no striking advances were found since the Parsons et al. (2012) report in relation to assessing impact on students.

In order to gain richer and more nuanced understandings of the impacts of CPD, researchers have called for new ways of collecting data about academic development 
activities. The use of qualitative data is encouraged to develop better understandings of commonalities and variances engendered by different approaches and in different HE CPD contexts (Chalmers, 2008; Shavelson, 2010). Bamber (2013, p. 7) advocates 'evidencing value' beyond simply a narrow focus on measuring satisfaction through quantitative measures. Sword (2008, p. 89) suggests the assemblance of a 'comprehensive educational archive' including materials such as student feedback, student assignments, reflective accounts from alumni and longitudinal questionnaire data can help to build a picture of impact over time. Encouraging reflexive approaches that consider both soft and hard outcomes alongside immediate and longer-term influences on thinking and changes to practice are advocated as a more holistic approach to evaluation (Bamber, 2013). Measuring the 'soft' impacts, such as increased self-confidence, self-efficacy, thinking differently, and a willingness to change practice, all of which benefit student learning, are challenging and require greater attention to be placed upon the process and the outcomes of CPD (Bamber, 2013). Gaining insights into institutional reward and recognition policies, and possible connections with CPD activities, are also seen as essential to understanding institutional framing of CPD (Cashmore, Cane \& Cane, 2013).

In this paper we report the outcomes of a UK-wide survey designed to benchmark current practice in evaluating teaching-related CPD. This study was part of a project funded by the Higher Education Academy which sought to understand the range of ways teaching-related CPD is evaluated across the HE sector (Kneale, Winter, Turner, Spowart \& Muneer, 2016). We draw on this data to examine approaches used to evaluate teaching-related CPD, considering specifically issues relating to the timing, methods and focus of such work. We consider the implications of the findings for future evaluation practice, highlighting the need for institutional approaches which 
promote synergies between systems of reward and recognition and appraisal. We conclude by posing questions around the role of students in the provision and evaluation of teaching-related CPD.

\section{Methodology}

This study was informed by the works of Guskey (2000) and Kreber and Brook (2001), which have been influential in shaping evaluation practice across different education sectors. Guskey (2000) identifies five levels of potential impact including:

- $\quad$ Participant satisfaction or reaction to the CPD;

- $\quad$ Participants' conceptual change in terms of beliefs about teaching and learning;

- $\quad$ Broader institutional changes.

- $\quad$ Changes to participants' teaching practices;

- $\quad$ Changes to students' learning and performance;

Kreber and Brook's evaluation framework covered the same categories of impact; however, importantly they added a sixth category - students' perceptions of staff's teaching performance. These frameworks informed the research questions that underpinned the survey reported here:

1. What teaching-related CPD is currently offered in HEIs?

2. How is the impact of CPD currently evaluated?

3. To what extent (if any) do institutional policies support teaching-related CPD?

4. To what extent (if any) are students involved in teaching-related CPD? As suggested above, CPD falls into two broad categories: accredited provision (e.g. accredited courses for new lecturers / recognition frameworks) and non-accredited 
provision (e.g. SoTL, conference attendance, peer review, mentoring etc.) (Chalmers, 2011). The survey was designed to capture details on an institution's primary accredited and non-accredited offers, and the methods used to evaluate these. This is a potential limitation of the study; however, it was not feasible to ask detailed questions about the evaluation of all teaching-related CPD activities.

The survey was administered online using Survey Monkey; it was open for responses for a 2-week period in February 2015, targeting those with a remit for academic development in HE in the UK. The focus on UK academic development was intentional as within the UK the UK Professional Standards Framework (UKPSF) is used by organisations such as the Higher Education Academy (HEA) and Staff and Educational Development Association (SEDA) to accredit their CPD provision, and increasingly underpins a considerable amount of lecturer CPD (HEA, 2011; Hibbert and Semler, 2016). The survey was disseminated via online mailing lists used by the UK academic development community (e.g. SEDA, HEA and regional educational development networks). Anecdotally these are recognised as being 'active' mailing lists, supporting regular discussion around contemporary issues relevant to the academic development community and reaching the full range of HE providers. The survey was targeted at academic development communities as they were likely to be involved in leading / supporting lecturer CPD, and have institutional oversight of CPD provision.

A response rate of $16 \%$ from an approximated population of 1150 (based on the recipients signed up to the SEDA mailing list) was obtained. This equated to 189 responses received from CPD providers in teaching and research-focused universities, FE colleges and private providers. Of these 189 responses, 142 were useable after the removal of incomplete and non-UK responses. Though this response rate is slightly lower than that obtained by related studies (e.g. Kandlbinder \& Peseta, 2009), given the 
low response rates documented for online surveys (e.g. Nulty, 2008), this is not uncommon and was deemed sufficient by the research team and the funding body, the HEA.

Respondents were categorised to facilitate analysis based on groupings used within the sector to describe or identify HE providers (e.g. Million+/Russell Group). Table 1 summarises the response rate for each grouping. Due to the limited response rate from HE providers categorised as representing 'FE colleges', 'Private Providers' and the 'unaligned/unspecified institutions', subsequent comparisons between institutions focused on respondents drawn from 'old/post-1964/Russell group' and 'post1992/Million+/New2010/University Alliance’ institutions (see Table 1).

\section{INSERT TABLE 1 HERE}

Table 2 lists key questions from the audit along with the response rates from the 'old/post-1964/Russell' group and 'post-1992/Million+/New2010/University Alliance' group.

\section{INSERT TABLE 2 HERE}

Data were analysed using a combination of methods using SPSS version 21.0. Initially frequency counts and percentages were calculated and reviewed to identify patterns within the data. A point-biserial correlation was also undertaken to test for relationships within the data.

\section{Findings}

The context of teaching-related CPD 
Lecturers from the 'post-1992/Million+/New2010/University Alliance' institutions were significantly more likely to have formal teaching qualifications compared to those in research-focused institutions $\mathrm{HE}^{1}$. These institutions were more consistent in setting expectations around CPD for staff in their different teaching and learning roles (including experienced staff), as compared with research-focused institutions. This resonates with the documented trajectory of practices to professionalise teaching and learning (Gosling, 2009).

Institutional priorities (articulated through teaching and learning strategies) shaped the majority of CPD offers ( $82 \%$ of accredited offers and $81 \%$ of non-accredited offers). Given that academic developers often have an integral role developing such strategies (Gosling, 2009) this is not unanticipated. Familiarising newcomers to their institutional context for example, is one important function of CPD (Smith, 2010). Accredited offers commonly drew on the UKPSF and evidence-based practice (91\% and 74\% respectively). Conversely, non-accredited offers tended to be more influenced by internal priorities, such as those of the educational development units and teaching and learning committees (54\% of all non-accredited CPD offers).

\section{Focus, timing and methods of evaluation}

The teaching-related CPD reported by respondents from all institution types analysed echoed those activities documented within the literature (Parsons et al., 2012). Most respondents, $81 \%$ of those from 'old/post-1964/Russell group' and 71\% of those from the 'post-1992/Million+/New2010/University Alliance' group focused their evaluation activities on formal CPD provision aligned with the UKPSF, such as teaching preparation programmes (e.g. Post Graduate Certificates) and in-house accreditation schemes. These are areas of CPD often perceived as core to Academic Development work (Gosling, 2009), and activities individuals are most likely to engage with due to institutional drivers including probation and promotion (Smith, 2010; McKenna \& Hughes, 2015). These CPD activities also afford the 'recognised status' institutions are

\footnotetext{
${ }^{1}$ point bi-serial correlation coefficient $r_{p b}=.466 ; p<.01$
} 
now required to report as part of their data return to the Higher Education Statistics Association in the UK (HESA, 2012).

Activities such as teaching and learning workshops, teaching and learning conferences, peer review, teaching development grants and mentoring, were not subject to the same level of evaluation. Only 17\% of respondents from each of the 'old/post-1964/Russell' and 'post-1992/Million+/New2010/University Alliance' groups described their method of evaluating these activities. Although these informal CPD activities are common across the sector, and serve an important enhancement function, engagement tends to be voluntary and driven by individual academics rather than by institutional priorities (Parsons et al., 2012). This distinction may inform the choices about which activities are systematically evaluated.

Additionally, the duration of the CPD activity appears to partly determine the frequency of evaluation and when it occurs. Those activities that were evaluated tended to be reviewed at the end of a CPD activity (Figure 1). Furthermore, accredited programmes, which tended to be of longer duration, were more likely to be evaluated twice or three times over the span of the programme - though this represented a minority of respondents' activity (Figure 1). Most non-accredited offers on the other hand were normally evaluated only once, at the end of the offer.

\section{INSERT FIGURE 1 HERE}

Figure 1: Use of evaluation with accredited and non-accredited CPD activities

Most evaluation occurred immediately after the CPD activity and focused on participant satisfaction (81\%), changes in beliefs about teaching and learning $(55 \%)$ and perceived changes in teaching practice (66\%). Questionnaires were most commonly used to evaluate CPD provision. As these generally capture only brief reflections they provide a limited evaluation of practice (Amundson \& Wilson, 2012; Chalmers \& Gardiner, 2015). 
There was also a distinct lack of initial benchmarking. Only $6 \%$ of respondents conducted evaluations before the start of a CPD activity. Benchmarking participants' knowledge, experience and expectations of a CPD activity is essential to facilitate measurement of impacts and determine the extent to which transfer takes place (De Rijdt et al., 2013). This takes time and requires forward planning, and whilst the need for this was recognised, the survey findings demonstrate it rarely happened (Figure 1). Similarly, only $15 \%$ of respondents evaluated the impact of their CPD longitudinally, citing the challenges and time-consuming nature of this type of measurement.

Those engaging in longitudinal evaluations (15\% of audit respondents), were moving away from closed-questionnaires capturing satisfaction to qualitative measures including interviews and focus groups. Only $29 \%$ of evaluations conducted at the conclusion of a CPD activity involved interviews and focus groups, compared to $50 \%$ of the longitudinal evaluations. These are methods recognised as leading to nuanced insights on potential impacts (Bamber, 2013).

Programmes leading to accreditation through the UKPSF, funded research projects and teaching fellowship schemes represented CPD activities that were evaluated longitudinally. Evaluation approaches reported included: mentor catch-ups with participants; questionnaires; feedback from discipline-specific learning and teaching committees; and analysis of data in annual teaching and learning department reports.

\section{INSERT FIGURE 2 HERE}

When the findings are analysed using Guskey's (2000) and Kreber and Brook's (2001) levels, it is evident that institutions engaged in longitudinal evaluation tend to focus on broader impacts on the institution and student learning (Figure 2). These are widely recognised as challenging areas in which to determine impact (Parsons et al., 2012; Trigwell, Caballero Rodriguez \& Han, 2012). Effective evaluation is reliant on alignment with the aims of a CPD activity and the aims of the evaluation (Guskey, 2000). These differing focal points signal a potential mismatch between the goals of a CPD activity and what is evaluated. In order to achieve synergies between the design and intended outcomes of an evaluation, over longitudinal timescales, institutional buyin is necessary (De Rijdt et al., 2013). Additionally, institutional resources, review 
cycles and agendas frequently determine the nature and timing of evaluation, all of which may inhibit 'proper longitudinal study'.

Finally, it is also possible to adopt a holistic approach to understanding impact in which findings from evaluations of CPD activities can be viewed in light of data from existing institutional and national datasets. Trigwell et al. (2012), and Chalmers and Gardiner (2015) argue that the use of multiple indicators (e.g. staff attainment, teaching prizes, student satisfaction data, and performance and retention data) enable a richer and more nuanced account of the impacts of CPD. Given most institutions are required to collect such data these are potentially readily available information sources that could be drawn on. Nonetheless, our findings revealed little evidence of the use of these additional datasets as a means of evaluating the impact of CPD.

\section{Institutional policies to support teaching-related CPD}

The ambition to develop workforce skills, particularly in relation to the requirements of the new Teaching Excellence Framework in the UK (BIS, 2016), may represent a key driver for the promotion of CPD and the measurement of its effectiveness (De Ridjt et al., 2013). Links can also be made between moves to enhance teaching and learning, individual development and reward and recognition (Turner \& Gosling, 2012). Some forms of non-accredited CPD (e.g. support for SoTL, conference attendance) may be presented as rewards for individuals' commitment to teaching and learning (Turner \& Gosling, 2012). Likewise, successful engagement with accredited CPD can contribute to a case for promotion (Smith, 2010; Spowart et al., 2015). These have been implicit in government policy (e.g. Browne, 2010; Dearing, 1997) which have also promoted the professionalization of teaching and learning in HE (Gosling, 2009).

Respondents cited student awards (65\%) and to a lesser extent, institutionally bestowed awards (54\%), as the main rewards used within their institution. This is a notable finding as although institutionally bestowed awards have a long history and have been widely used to reward and recognise teaching (Turner \& Gosling, 2012), student-led teaching awards are a relatively recent introduction (Swain, 2013). Their use is determined by local student unions, and whilst they are recognised as a 'powerful tool in empowering students to define what quality feels like in their institution' (Swain, 
2013, p.9), a recent study has questioned the extent to which they actually serve to reward or cause derision (Madriaga \& Morely, 2016). Both of these forms of rewards are centred on the individual, therefore determining wider impacts may be challenging (Turner \& Gosling, 2012).

Overall, the rhetoric in government policy, as well as the evidence from respondents, demonstrates a focus on the individual. Whilst in some respects this is to be expected, many of the longer terms goals of CPD, as advocated by Guskey (2000), Kreber and Brook (2001) and others, is to achieve institutional change in teaching and learning. This requires an alignment of a range of institutional policies and practices. Additionally, policies that focus primarily on the development of individuals to effect systemic educational change and fail to address the broader cultural contexts at the level of department, faculty, and institution are unlikely to succeed (Trowler \& Bamber, 2005, p. 84). An alignment of a range of institutional policies and practices is required if CPD is to have a sustained impact.

There is an overriding need to consider evaluation as a collaborative venture. In doing this, CPD would need to be reframed to recognise both the benefits to the individual and the institution. This would ensure clarity about what an evaluation is trying to measure from the outset, preventing the mismatches in the focus of evaluation activities over time.

\section{The role of the student voice in evaluating teaching-related CPD}

The goal of much teaching-related CPD is to enhance the student experience (Parsons et al., 2012). However, our data suggests the contribution of students to evaluation is minimal (Table3). There are some examples of student engagement in teaching-related CPD in the literature (e.g. Campbell et al., 2009; Havergal, 2015; Peat, 2011); however, these studies are limited in scale and scope.

Most evaluation is concentrated on the participants' experiences and the influence it may have had on their practice, and their colleagues' practices. The apparent absence of students in the evaluation process, either directly or indirectly (e.g. through inclusion of reflections on NSS data), is a notable oversight and highlights a clear direction in 
which evaluation practices need to develop in the future. Engaging students in CPD raises interesting issues around creating an environment in which they are welcome, as well as logistical issues relating to the timing of CPD in relation to student availability and recruitment (Campbell et al., 2009). However, these issues are not insurmountable and relate to the careful framing of student engagement as explored in recent research by Turner et al. (2016).

However, including students in evaluating lecturer CPD does bring to the fore a number of wider issues that need attention. There needs to be an awareness of the potential tension between quality enhancement and quality assurance when gathering data that ultimately could be used for quality monitoring. This connects back to institutional drivers for evaluation, and the need for sensitivity around who undertakes the evaluation, and how it is approached.

\section{Conclusion and future research}

Whilst the massification of HE and constraints on funds and resources means that there is a high demand for performance-based accountability (Alexander, 2000), evaluation practices in UK HE institutions do not appear to have shifted in line with this expectation. This work has been undertaken at a time when teaching quality is increasingly under scrutiny. In 2017 the UK government instigated the Teaching Excellence Framework (TEF) which intends to provide a measure of quality for teaching in UK HE with universities asked to evidence teaching quality, learning environment, student outcomes and learning gain (BIS 2016). As academic development is the primary vehicle by which teaching is enhanced in UK HE, evidencing its value is an important political as well as practical consideration.

Without adequate evaluation tools aligned towards this goal of evidencing impact and value, academic developers are doing themselves an injustice in failing to provide a coherent narrative and clear cues regarding their 'significant contribution to overall organizational development and performance' (Stefani, 2013, p. 294). Additionally, this study demonstrates that where evaluation of teaching-related CPD is undertaken, the tendency is to focus on the lower levels of Gusky's (2000) and Kreber \& Brook's (2001) evaluation frameworks such as participant satisfaction with the CPD and 
conceptual changes in participants' beliefs about teaching and learning. Significantly, there is relatively little evidence of a consideration of the top levels of the frameworks, particularly the impact of CPD on students' learning and performance.

The breadth and nature of CPD also complicates the analysis of its impact. For example, there are substantial challenges in considering impact across an institution when the nature and subject focus of CPD work takes on different guises. The programmes for new staff are likely to have good cohort sizes, enabling conclusions to be drawn. However, participants' engagement is unique ( Parsons et al., 2012; Smith, 2010) with staff attending from different disciplines. In addition, an individual's experience as an undergraduate and preferred methods of learning influence the ways in which they adopt and engage with new ideas (Smith, 2010).

Furthermore, school-led annual away-days, university-wide development sessions, internal and external workshops and conferences for more experienced staff are likely to be more episodic, irregular engagements for HE staff. Topics depend on university strategic imperatives, and the personal interests of the staff involved (Gosling, 2009). Where there is a major change, as in the introduction of new software, or a process is mandated (e.g. all student submissions will be online) then uptake and effectiveness measures can be made.

Whilst it is accepted that measuring impact is challenging, it is, nonetheless evident that evaluation across the sector is poorly conceptualised and misunderstood. With relatively few exceptions, staff undertaking evaluations are operating in isolation, and without support and guidance to assist them to engage in more meaningful evaluation practices. Whilst there are myriad of evaluation frameworks in existence (e.g. De Rijdt et al. 2013; Guskey, 2000; Trigwell et al., 2012; Kreber \& Brook, 2001) they remain, as Parsons et al. (2012) argued, theoretical models with limited application in the sector.

This research has identified that most teaching-related CPD is evaluated through postevent questionnaires, sometimes called 'happy sheets'. These tend to focus on participants' immediate satisfaction with the teaching, the resources provided and the 'housekeeping' at the event. While of immediate value to the event organiser, these findings contribute little to our understanding of the value CPD has for teaching and learning, and the impact of academic development on curriculum, learning outcomes 
and the student experience. Mapping impact requires reflection from staff who understand that tracking change is a valuable experience in its own right, and who therefore keep evidence of practice developments. Where this is a professional body requirement, for example in medicine and dentistry, the processes are more likely to be embedded.

Training for staff in the ways in which impact can be captured therefore needs to be integrated into academic development from the start and reinforced at every stage. Arguably being able to evidence one's effectiveness in practice and ongoing enhancement should be part of an academic's professional activity and evidenced in appraisal and promotion processes. Additionally, attention to the upper levels of the Gusky’s (2000) and Kreber and Brook's (2001) frameworks would enhance understanding of the impact of CPD on institutional policies, practices and cultures as well as upon student outcomes. While problematic and requiring longer evaluation cycles than this research permitted, such categories should be priorities for future research and development into the evaluation of teaching-related CPD in higher education.

Finally, the contributions students can make to staff CPD is an area that has received limited attention and could be usefully explored to better align CPD and the student voice (Turner et al., 2016). The opportunities, or even potential for students to engage with teaching-related CPD are few and far between, as reflected in the limited discussion of this subject across the Educational Development community. Although projects (Peat, 2011; Campbell et al., 2009) have sought to promote student engagement with the CPD, there are many barriers that need to be overcome before this can happen. Likewise, student awareness of staff CPD is implicit. Therefore, in order to determine an impact on student learning, even at a basic level, we need to raise student awareness of the CPD lecturing staff engage with and the impacts it can have on their teaching and learning.

\section{References}

Alexander, F. K. (2000). The changing face of accountability: Monitoring and assessing institutional performance in higher education. Journal of Higher Education, 71(4), 411431. 
Bamber, V. (2013). Evidencing the value of educational development, SEDA Special 34. London: SEDA.

Buckley, A. (2014). UK Engagement Survey 2014: The second pilot year, York: Higher Education Academy.

Brew, A. (2007). Evaluating academic development in a time of perplexity. International Journal for Academic Development, 12(1), 69-72.

Browne Report. (2010). Securing a sustainable future for Higher Education: An Independent Review of Higher Education Funding and Student Finance. Retrieved June 3, 2016, from https://www.gov.uk/government/uploads/system/uploads/attachment_data/file/422565/b is-10-1208-securing-sustainable-higher-education-browne-report.pdf

Campbell, F., Eland, J., Rumpus, A., \& Shacklock, R. (2009). Hearing the student voice: involving students in curriculum design and delivery. Edinburgh Napier University. Retrieved March 4, 2016, from http://www.sparqs.ac.uk/ch/E3\%20Hearing\%20the\%20student\%20voice\%20involving $\% 20$ students\%20in\%20curriculum\%20design\%20and\%20development.pdf

Cashmore, A., Cane, C., \& Cane, R. (2013). Rebalancing promotion in the HE sector: is teaching excellence being rewarded?. Genetics Education Networking for Innovation and Excellence: the UK's Centre for Excellence in Teaching and Learning in Genetics (GENIE CETL), University of Leicester. The Higher Education Academy.

Chalmers, D. (2008) Indicators of university teaching and learning quality. Sydney, NSW: Australian Learning and Teaching Council. Retrieved March 4, 2016, from http://www.catl.uwa.edu.au/projects/tqi

Chalmers, D. (2011). Progress and challenges to the recognition and reward of the scholarship of teaching in higher education. Higher Education Research and Development, 30, 25-38.

Chalmers, D. \& Gardiner, D. (2015). The measurement and impact of university teacher development programs. Educar, 51(1), 1-28. 
Dearing Report. (1997). Report of the National Committee of Inquiry into Higher Education. Retrieved June 3, 2016, from http://www.leeds.ac.uk/educol/ncihe/

Department for Business, Innovation and Skills (BIS) (2016). Teaching Excellence Framework: Technical consultation for year two. Available from. https://www.gov.uk/government/consultations/teaching-excellence-framework-year-2$\underline{\text { technical-consultation }}$

De Rijdt, C., Stes, A., van der Vleuten, C. \& Dochy, F. (2013). Influencing variables and moderators of transfer of learning to the workplace within the area of staff development in higher education: Research review. Educational Research Review, 8(1), 48-74.

Fenstermacher, G. D., \& Berliner, D. C. (1985). Determining the value of staff development. The Elementary School Journal, 85(3), 281-314.

Fink, L.D. (2013). Innovative ways of assessing faculty development. New Directions for Teaching and Learning, 2013(133), 47-59.

Gibbs, G. (2010). Dimensions of quality. York: The Higher Education Academy.

Gosling, D. (2009). Educational development in the UK: A complex and contradictory reality. International Journal for Academic Development, 14(1), 5-18.

Guskey, T. R. (2000). Evaluating professional development. Corwin Press.

Havergal, C. (2015). Should students be partners in curriculum design? Times Higher Education. Retrieved February 29, 2016, from

https://www.timeshighereducation.com/features/should-students-be-partners-incurriculum-design

Hibbert, P., \& Semler, M. (2016). Faculty development in teaching and learning: the UK framework and current debates. Innovations in Education and Teaching International, 53(6), 581-591.

Higher Education Academy (2011). The UK Professional Standards Framework for teaching and supporting learning in higher education. Retrieved June 3, 2016, from https://www.heacademy.ac.uk/sites/default/files/downloads/ukpsf_2011_english.pdf 
HESA (2012). Changes made to the staff record for 2012/13. Higher Education Statistics Agency. Retrieved from

http://www.hesa.ac.uk/component/option,com_studrec/task,show_file/Itemid,233/mnl,1 2025/href,Changes.html/

Hoecht, A. (2006). Quality assurance in UK higher education: Issues of trust, control, professional autonomy and accountability. Higher Education, 51(4), 541-563.

Hughes, J., McKenna, C., Kneale, P., Winter, J., Turner, R., Spowart, L., \& Muneer, R. (2016). Evaluating teaching development in higher education: Towards impact assessment (Literature Review). York: Higher Education. Retrieved June 3, 2016, from https://www.heacademy.ac.uk/resource/evaluating-teaching-development-highereducation

Kandlbinder, P., \& Peseta, T. (2009). Key concepts in postgraduate certificates in higher education teaching and learning in Australasia and the United Kingdom. International Journal for Academic Development, 14(1), 19-31.

Kneale, P., Winter, J., Turner, R. Spowart, L., and Muneer, R. (2016) Evaluating teaching development activities in higher education: a toolkit. Higher Education Academy: York.

Kreber, C. \& Brook, P. (2001). Impact evaluation of educational development programmes. International Journal for Academic Development, 6(2), 96-108.

Madriaga, M., \& Morley, K. (2016). Awarding teaching excellence: 'What is it supposed to achieve?' Teacher perceptions of student-led awards. Teaching in Higher Education, 1-9.

McKenna, C. \& Hughes, J. (2015). The locations and identity construction of academic developers: Findings from the ExILED (Exploring the Identities and Locations of Educational Developers) project. SEDA Report.

Nulty, D. (2008). The adequacy of response rates to online and paper surveys: What can be done? Assessment and Evaluation in Higher Education, 33(3), 301-314. 
Parsons, D., Hill, I., Holland, J., \& Willis, D. (2012). Value of teaching development programmes in Higher Education. Higher Education Academy: York.

Peat, J. (2011). New to the field: Integrating the student voice into the PG Cert. Educational Developments, 12(4).

Shavelson, R. (2010). Measuring college learning responsibly: Accountability in a New Era. California, Stanford University Press.

Smith, J. (2010). Forging identities: the experiences of probationary lecturers in the UK. Studies in Higher Education, 35, 577-591.

Spowart, L., Turner, R., Shenton, D., \& Kneale, P. (2015). 'But I have been teaching for 20 years...': Encouraging teaching accreditation for experience staff working in higher education. International Journal for Academic Development, DOI: 10.1080/1360144X.2015.1081595.

Stefani, L. (2013). Performance measurement for academic development: risk or opportunity? International Journal for Academic Development, 18(3), 294-296.

Swain, J. (2013). Student lead teaching awards: Project landscape. National Unions of Students: London.

Sword, H. (2008). The longitudinal archive. International Journal for Academic Development, 13(2), 87-96.

Sword, H. (2014). Dancing on the bottom line: An unruly cost-benefit analysis of three academic development initiatives. Higher Education Research and Development, 33(4), 783-793.

Trigwell, K., Caballero Rodriguez, K., \& Han, F. (2012). Assessing the impact of a university teaching development programme. Assessment \& Evaluation in Higher Education, 37(4), 499-511.

Trowler, P. \& Bamber, V. (2005) Compulsory higher education teacher training: Joined-up policies, institutional architectures and enhancement cultures. International Journal for Academic Development, 10(2), 79-93. 
Turner, R. \& Gosling, D. (2012). Rewarding excellent teaching: the translation of a policy initiative in the United Kingdom. Higher Education Quarterly, 66, 415-430.

Turner, R., Spowart, L., Winter, J., Muneer, R., Harvey, C., \& Kneale, P. (2016). The lecturer should know what they are talking about': Student union officers perceptions of teaching-related CPD and implications for practice. Innovations in Education and Teaching International. Special Issue: Evaluation. Published online: 20 Nov 2016. http://dx.doi.org/10.1080/14703297.2016.1257948 